\title{
Atorvastatin and cardiovascular risk in the elderly - patient considerations
}

\author{
Subroto Acharjee \\ Francine K Welty \\ Division of Cardiology, Beth Israel \\ Deaconess Medical Center, Boston, \\ MA, USA
}

\begin{abstract}
Elderly individuals are at increased risk of coronary heart disease (CHD) and account for a majority of CHD deaths. Several clinical trials have assessed the beneficial effects of statins in individuals with, or at risk of developing, CHD. These trials provide evidence that statins reduce risk and improve clinical outcomes even in older patients; however, statin therapy remains under-utilized among the aged. Atorvastatin has been widely investigated among the older subjects and has the greatest magnitude of favorable effects on clinical outcomes of CHD. The pharmacokinetic properties of atorvastatin allow it to be used every other day, a factor which may decrease adverse events and be especially important in the elderly. The purpose of this article is to review the evidence available from randomized clinical trials regarding the safety and efficacy of atorvastatin in primary and secondary prevention of CHD and stroke in older patients and to discuss issues such as drug interactions, patient compliance and cost-effectiveness, which affect prescription of lipid-lowering therapy among older patients.
\end{abstract}

Keywords: atorvastatin, statins, HMG-CoA reductase inhibitors, coronary heart disease, elderly patients

\section{Introduction}

The proportion of older persons $(>60)$ is projected to more than double worldwide over the next half century. The older population is expanding faster than the total population throughout the world and this difference in growth rates is increasing (UN 2001). Data from the Framingham Heart Study show that the cumulative risk of CHD rises steeply after age 60 years until age 90 years, at which time cumulative risk seems to plateau (Lloyd-Jones et al 1999). Therefore, such a shift in the demographic profile will lead to increased incidence of cardiovascular disease, including CHD, heart failure, and stroke (Bonow et al 2002). Heart disease (30.4\%) and stroke (7.4\%) were the first and third leading causes of mortality and morbidity in 2004 among adults aged 65 years and older in the US (Miniño et al 2007). Incidence of new CHD events is greatest among persons $\geq 65$ years of age and this group accounts for $83 \%$ of CHD deaths (Rosamond et al 2007). New modalities of treatment have managed to reduce death rates from acute coronary events. This has resulted in people with CHD living longer leading to increased prevalence among the elderly. Besides advancing age, other cardiovascular risk factors are also more prevalent among the elderly population. Dietary indiscretion along with sedentary lifestyle has led to increased prevalence of the metabolic syndrome among older adults (Ford et al 2004). Insulin resistance, abdominal obesity and lipid abnormalities accompany this syndrome, which are known CHD risk factors.

Elevated total serum cholesterol has been associated with risk of CHD in older men and women in various large-scale studies (Castelli et al 1989; Benfante et al 1990; Rubin et al 1990; Frost et al 1996; Houterman et al 1999). The Framingham data and the Systolic Hypertension in the Elderly Program (SHEP) have demonstrated that high levels of low-density lipoprotein cholesterol (LDL-C) and low levels of high-density 
lipoprotein cholesterol (HDL-C) were associated with CHD risk in older patients (Castelli et al 1989; Frost et al 1996). However, others have pointed out that the association between total serum cholesterol and risk of coronary artery disease diminishes with increasing age (Shipley et al 1991; Kronmal et al 1993; Assmann et al 1998). Thus, the rationale for treatment of elevated cholesterol levels in the elderly is less clear.

Therapy with statins has been shown to effectively reduce the incidence of major coronary events in primary prevention and particularly in secondary prevention settings, in several prospective randomized clinical research studies (Pedersen et al 1994; Shepherd et al 1995; Sacks et al 1996; Downs et al 1998; LIPID Study Group 1998; HPSCG 2002; Shepherd et al 2002; Sever et al 2003; Cannon et al 2004; Colhoun et al 2004; LaRosa et al 2005; Deedwania et al 2007). Unfortunately, the early statin trials have suffered from significant age and gender bias, as most of them recruited relatively small numbers of women and elderly subjects, resulting in inadequate representation of that group of patients (Bandyopadhyay et al 2001). In the recent secondary prevention guidelines from the American Heart Association (AHA) and the American College of Cardiology (ACC), the writing group has acknowledged this fact and has urged physician and patient participation in trials that will provide additional evidence for lipid-lowering therapy in the elderly (Smith et al 2006). Physicians have been reluctant to prescribe these drugs in older adults due to a perceived lack of indication (Cournot et al 2006). There has been a belief that cholesterol lowering therapy must be continued for prolonged periods before any beneficial effect can be observed on the underlying atherosclerosis. There are also concerns regarding increased risk of adverse events (Cournot et al 2006) and drug interactions, as well as the effect of statins on the various comorbidities in this age group. Patient non-compliance and adherence to long term statin treatment are other important considerations (Benner et al 2002; Jackevicius et al 2002; Benner et al 2005). Doubts have been raised about the cost-effectiveness of statin use for primary prevention in the elderly. Studies suggest that statins remain largely underutilized in elderly patients even in secondary prevention settings, where they have proven benefits (Ghosh et al 2002; Rasmussen et al 2005). Data from the National Registry of Myocardial Infarction 3 (Fonarow et al 2001) and the Global Registry of Acute Coronary Events (GRACE) (Avezum et al 2005) further support this assertion.

In this review, we look at the elderly subgroup from the major primary and secondary prevention statin trials, with a special focus on atorvastatin. We discuss the basic mechanisms of action of atorvastatin as well as issues of safety, tolerability, drug interactions and patient compliance. We also make recommendations regarding management strategies in older CHD patients, and place of atorvastatin in therapy.

\section{Pharmacology of statins and pleiotropic effects}

Atorvastatin is a potent intrinsically active inhibitor of 3-hydroxy-3-methylglutaryl coenzyme A (HMG-CoA) reductase which is the rate-limiting enzyme in de novo cholesterol synthesis. This enzyme inhibition lasts for 20-30 hours, given that its elimination half-life (14 hours) is longer than all statins except rosuvastatin (19 hours), and its active metabolites persist for even longer periods of time (Lea et al 1997). HMG-CoA reductase inhibitors reduce the production of mevalonic acid from $\mathrm{HMG}-\mathrm{CoA}$, resulting in a reduction in hepatic cholesterol synthesis. This in turn results in a compensatory increase in the expression of highaffinity LDL receptors on hepatocyte membranes leading to an increased catabolism of LDL and its precursors, resulting in decreased LDL production (Brown et al 1986). Reductions in the hepatic pool of cholesterol have been associated with a decrease in the rate of production of very-low-density lipoprotein (VLDL) by the liver (Thompson et al 1996). Atorvastatin decreases hepatic apo B secretion, which lowers VLDL production (Conde et al 1996).

In addition to decreasing cholesterol levels, statins affect atherosclerosis by several other effects such as plaque stabilization, reduced inflammation, reversal of endothelial dysfunction, and decreased thrombogenicity. These effects seem unrelated or only partially related to the lipid lowering effect.

Using coronary intravascular ultrasound, atorvastatin has been shown to retard the progression of plaque volume and increase plaque hyperechogenicity (Schartl et al 2001; Nissen et al 2004). Increased hyperechogenicity correlates with change in plaque composition from an unstable lipidrich lesion to a plaque with a larger fraction of calcium and collagen. Such a change increases stability and decreases the tendency for plaque disruption leading to an acute CHD event. The Reversal of Atherosclerosis With Aggressive Lipid Lowering (REVERSAL) trial (Nissen et al 2004) showed that the rate of progression was slower with atorvastatin $80 \mathrm{mg}$ /day compared to pravastatin $40 \mathrm{mg} /$ day, at any level of LDL-C reduction suggesting the role of pleiotropic effects in the improved outcome. 
Atorvastatin therapy reduces the serum $\mathrm{C}$ reactive protein (CRP) concentration significantly, which suggests an anti-inflammatory action (Jialal et al 2001). Atorvastatin $80 \mathrm{mg} /$ day reduced CRP levels to a greater extent than either simvastatin $40 \mathrm{mg}$ /day or pravastatin $40 \mathrm{mg}$ /day in the Atorvastatin versus Simvastatin on Atherosclerosis Progression (ASAP) (van Wissen et al 2002) and REVERSAL (Nissen et al 2004) trials, respectively. The decrease in CRP was significantly correlated with reduction of intima media thickness of carotid artery segments in the ASAP study. In the Trial of Atorvastatin in Rheumatoid Arthritis (TARA) study, atorvastatin caused a clinically apparent reduction in inflammation in rheumatoid arthritis patients, along with reduced CRP and erythrocyte sedimentation rate (McCarey et al 2004). Reduction in expression of endothelial adhesion molecules (ICAM-1, VCAM-1, E-selectin and $\mathrm{P}$-selectin) also contributes to the anti-inflammatory effect (Seljeflot et al 2002).

Atorvastatin improves the endothelial dysfunction associated with atherosclerosis and this effect is seen within 24 hours, before its effects on CRP and cholesterol become evident (Marchesi et al 2000; Laufs et al 2001). Statins prevent downregulation of endothelial nitric oxide synthase and may directly upregulate its activity, leading to increased bioavailability of nitric oxide. They also have an action on the endothelial progenitor cells (Martinez-Gonzalez et al 2007).

Atorvastatin decreases thrombogenicity and improves hemorrheological parameters within a few months of treatment. Decrease in whole blood viscosity and collageninduced platelet aggregation, improvement in red blood cell deformability and reduction in Von Willebrand factor (vWf) concentration are some of the possible mechanisms (Szapary et al 2004).

\section{Secondary prevention trials with atorvastatin}

Beneficial effects of atorvastatin have been widely investigated both in patients with stable CHD and in patients with recent acute coronary events. Table 1 summarizes the effects of atorvastatin on major clinical endpoints in various secondary prevention trials.

\section{Stable CHD with clinical endpoints}

The Study Assessing Goals in the Elderly (SAGE) trial was the first trial to specifically investigate intensive statin therapy in elderly CHD patients (Deedwania et al 2007). Eight hundred ninety three patients aged $65-85$ years with stable CHD, baseline LDL-C levels between $100 \mathrm{mg} / \mathrm{dL}$ and $250 \mathrm{mg} / \mathrm{dL}$ who had at least one episode of ischemia on baseline screening with 48-hour ambulatory ECG monitoring were randomly assigned to treatment with atorvastatin $80 \mathrm{mg} /$ day or pravastatin $40 \mathrm{mg} /$ day and followed up for 12 months. Compared with pravastatin, atorvastatintreated patients experienced significantly greater decreases in LDL-C (55\% vs $32 \%$ at 12 months), total cholesterol, triglycerides, and apolipoprotein B at months 3 and 12 (all $\mathrm{p}<0.001)$. The total duration of ambulatory myocardial ischemia (the primary efficacy parameter) was equally and significantly reduced from baseline in both groups (both $\mathrm{p}<0.001$ ) as early as 3 months with improvement persisting at one year. There was a $77 \%$ reduction in all-cause mortality ( 1.3 vs $4 \%$, hazard ratio [HR] $0.33,95 \%$ confidence interval [CI] 0.13-0.83, p=0.014) and a trend toward fewer major acute cardiovascular events (8.1 vs $11.2 \%$, HR 0.71 , 95\% CI $0.46-1.09, \mathrm{p}=0.114$ ) with atorvastatin relative to pravastatin at the end of month 12 . Thus, older men and women with CHD were shown to benefit with intensive atorvastatin therapy.

In the Treating to New Targets (TNT) study, 10,001 patients (3809 patients $\geq 65$ years) with $C H D$ and LDL-C $<130 \mathrm{mg} / \mathrm{dL}$ were randomized to receive atorvastatin $10 \mathrm{mg} /$ day or $80 \mathrm{mg} /$ day and followed up for a median of 4.9 years (LaRosa et al 2005). The high-dose atorvastatin group showed a lower mean serum LDL-C concentration ( 77 vs $101 \mathrm{mg} / \mathrm{dL}$ ) along with a $22 \%$ relative reduction in the rate of the composite primary end point of death from CHD, nonfatal non-procedure-related myocardial infarction (MI), resuscitation after cardiac arrest, or fatal or nonfatal stroke $(8.7 \%$ vs $10.9 \%$, HR $0.78,95 \%$ CI $0.69-0.89, \mathrm{p}=0.001)$. Reductions were also seen in non-fatal MI (HR 0.78, 95\% CI 0.66-0.93, p = 0.004) and fatal or nonfatal stroke (HR 0.75, CI 0.59-0.96, p=0.02). A secondary analysis of the TNT study in patients $\geq 65$ years of age demonstrated a 19\% reduction in relative risk (RR) for major cardiovascular events in favor of the high-dose atorvastatin group (HR 0.81, 95\% CI 0.67-0.98, p = 0.032) (Wenger et al 2007). Absolute risk reduction was similar in older and younger patients with intensive atorvastatin therapy $(2.3 \%$ in both groups). No statistically significant heterogeneity of treatment effect for age was seen for the primary outcome (or its individual components) or secondary outcomes. Elderly subjects in the atorvastatin $80 \mathrm{mg}$ /day group had lower rates of CHD death, nonfatal non-procedure-related MI, and fatal or nonfatal stroke, although the difference did not reach statistical significance. This trial also suggested that high-risk older patients with established CHD could benefit from intensive 


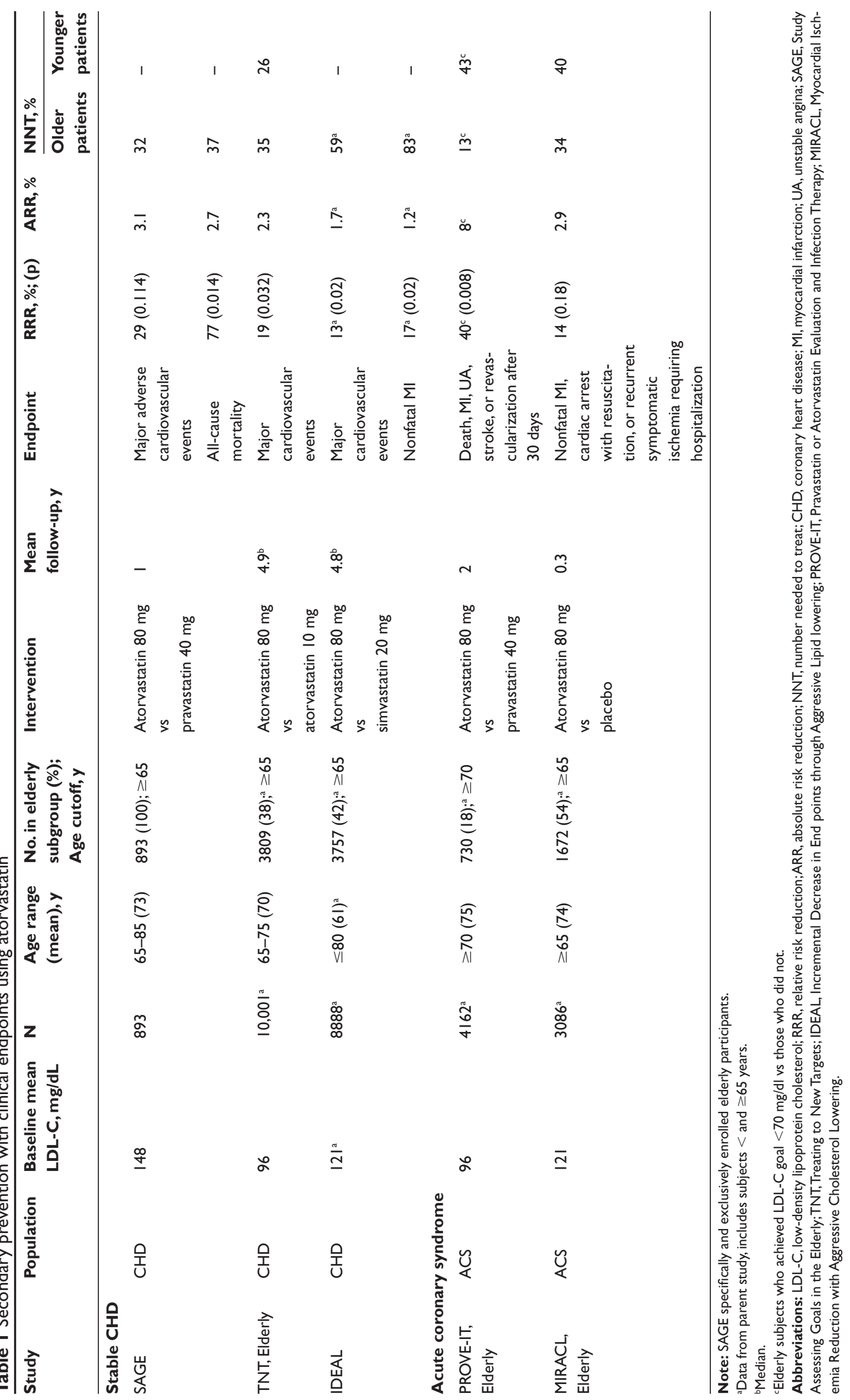


atorvastatin therapy and lowering LDL-C levels to less than $100 \mathrm{mg} / \mathrm{dL}$ could provide incremental clinical benefit.

The Incremental Decrease in End points through Aggressive Lipid lowering (IDEAL) trial recruited 8888 patients aged $\leq 80$ years with a history of acute MI, and randomly assigned them to receive high-dose atorvastatin $(80 \mathrm{mg} /$ day $)$ and usual-dose simvastatin (40 mg/day) (Pedersen et al 2005). Compared with simvastatin, atorvastatin-treated patients experienced significantly lower mean levels of LDLC (81 vs $104 \mathrm{mg} / \mathrm{dL}$ ), total cholesterol, and triglycerides (all $\mathrm{p}<0.001$ ) after a median follow-up of 4.8 years. The primary clinical outcome was time to first occurrence of a major coronary event defined as coronary death, hospitalization for nonfatal acute MI, or cardiac arrest with resuscitation. The primary outcome was nonsignificantly reduced with atorvastatin (9.3 vs $10.4 \%$, HR $0.89,95 \%$ CI $0.78-1.01$ ). There were significant reductions in rates of nonfatal acute MI (HR 0.83, 95\% CI 0.71-0.98, p=0.02) and major cardiovascular events (HR 0.87, 95\% CI 0.77-0.98, $\mathrm{p}=0.02$ ). No separate data were published regarding elderly participants in the study. However, a preliminary analysis by the authors did not reveal any statistically significant treatment group interactions by age.

\section{Stable CHD with atheroma volume as endpoint}

The Reversal of Atherosclerosis with Aggressive Lipid Lowering (REVERSAL) trial randomized 654 patients to receive pravastatin $40 \mathrm{mg} / \mathrm{d}$ or atorvastatin $80 \mathrm{mg} /$ day (Nissen et al 2004). Five hundred two had evaluable intravascular ultrasound examinations at baseline and after 18 months of treatment. The atorvastatin group experienced greater reductions in levels of LDL-C (46 vs 25\%), total cholesterol, triglycerides and apo B (all p < 0.001). CRP was reduced by $5.2 \%$ with pravastatin and $36.4 \%$ with atorvastatin $(\mathrm{p}<0.001)$. A significant percentage change in total atheroma volume (primary end point) occurred in the pravastatin group $(+2.7 \%, 95 \%$ CI $0.2 \%-4.7 \%, p=0.001)$, indicating progression of atherosclerosis compared to baseline. No progression was noted with atorvastatin and percentage change in total atheroma volume was negative $(-0.4 \%$, $\mathrm{CI}-2.4 \%$ to $1.5 \%, \mathrm{p}=0.98$ ). Thus, aggressive lipid-lowering with atorvastatin significantly reduced disease progression compared to pravastatin $(-0.4 \%$ vs $2.7 \%, p=0.02)$. Differences were seen between the treatment groups for secondary endpoints such as total atheroma volume $(p=0.02)$, change in percentage atheroma volume $(\mathrm{p}<0.001)$, and change in atheroma volume in the most severely diseased $10-\mathrm{mm}$ vessel subsegment ( $p<0.01$ ), all favoring the atorvastatin group. For 231 patients aged equal to or greater than the median age ( 56 years), change in atheroma volume was $4.8 \%$ with pravastatin $(\mathrm{p}<0.001)$ and $-1.5 \%$ with atorvastatin $(p=0.67)$. The therapeutic regimens were significantly different in this older group $(\mathrm{p}=0.01)$, but similar in younger patients $(p=0.75)$. Linear regression analysis indicated that, for any given level of LDL-C reduction, the progression rate was lower with atorvastatin compared with pravastatin for all patients. A subsequent analysis concluded that in addition to lipid lowering, the greater effect of atorvastatin on CRP might be responsible for slower disease progression (Nissen et al 2005).

\section{Acute coronary syndrome (ACS) with clinical endpoints}

The Pravastatin or Atorvastatin Evaluation and Infection Therapy Thrombolysis in Myocardial Infarction (PROVE IT-TIMI) 22 trial evaluated the effects of standard (LDL-C $<100 \mathrm{mg} / \mathrm{dL}$ ) versus intensive (LDL-C $<70 \mathrm{mg} / \mathrm{dL}$ ) lipid lowering using pravastatin $40 \mathrm{mg} / \mathrm{d}$ and atorvastatin 80 $\mathrm{mg} / \mathrm{d}$, respectively, in 4162 patients ( 730 patients $\geq 70$ years) hospitalized with ACS within the preceding 10 days (Cannon et al 2004). Patients were required to have a baseline total cholesterol concentration of $\leq 240 \mathrm{mg} / \mathrm{dL}$ if not on prior therapy or $\leq 200 \mathrm{mg} / \mathrm{dL}$ if on lipid-lowering therapy at the time of the ACS. After a mean follow-up of 2 years, median LDL-C levels decreased more with atorvastatin compared with pravastatin in statin-naïve patients (51\% vs $22 \%)$ as well as among patients previously on statin therapy $(32 \%$ vs $0 \%$ ). The primary end point was a composite of death from any cause, MI, documented unstable angina requiring rehospitalization, revascularization and stroke. The primary end point was reduced by $16 \%$ with atorvastatin relative to pravastatin $(22.4 \%$ vs $26.3 \%$, HR $0.84,95 \%$ CI $0.74-0.95$, $\mathrm{p}=0.005)$. The benefit of atorvastatin became apparent as early as 30 days after randomization and was consistent over time. Similar benefit or a trend toward benefit was seen in all the individual components of the primary end point with the exception of stroke. Post-hoc analysis of patients $\geq 70$ years of age revealed that a greater proportion of patients achieved the LDL-C goals at 30 days in the atorvastatin $80 \mathrm{mg}$ /day group versus those allocated pravastatin $40 \mathrm{mg} / \mathrm{d}(74.6 \%$ vs $27.7 \%, p<0.001$ ) (Ray et al 2006). Achievement of the LDL-C goal of $<70 \mathrm{mg} / \mathrm{dL}$ was associated with a $40 \%$ lower risk of death, MI, or unstable angina compared to older patients who did not reach goal (13.5 vs $21.5 \%$ absolute rates, respectively; HR $0.60,95 \%$ CI $0.41--0.87, \mathrm{p}=0.008$ ). 
To prevent 1 cardiovascular event, only 13 elderly subjects needed to achieve the LDL-C goal compared to 43 younger subjects. Thus, nearly 4 times as many acute events could be potentially prevented among the elderly by lowering LDL-C to $<70 \mathrm{mg} / \mathrm{dL}$ (80 vs 23 events prevented for every 1000 patients at goal over 2 years).

The Myocardial Ischemia Reduction with Aggressive Cholesterol Lowering (MIRACL) study was also done in the post-ACS setting. 3086 adults ( 1672 patients $\geq 65$ years) with unstable angina or non-Q-wave MI were randomized to 16 weeks of atorvastatin $80 \mathrm{mg}$ /day or placebo $24-96$ hours after hospital admission (Schwartz et al 2001). The primary end point (nonfatal infarction, cardiac arrest with resuscitation, or recurrent symptomatic ischemia requiring hospitalization) was significantly reduced with atorvastatin (14.8 vs $17.4 \%$, RR $0.84,95 \%$ CI $0.70-1.00, \mathrm{p}=0.048$ ) primarily due to a $26 \%$ reduction in recurrent ischemic events (RR $0.74,95 \%$ CI $0.57-0.95, \mathrm{p}=0.02$ ). A post hoc analysis of older patients in the study was done using treatment-byage heterogeneity tests (Olsson et al 2007). Similar relative reductions in the primary end point were seen in younger and older patients with atorvastatin $(22 \%$ vs $14 \%, p=0.62)$. The Number Needed to Treat (NNT) was 34 among the elderly, compared to 40 among younger subjects. There was no difference in treatment effect between these two groups for any of the individual components of the primary end point or secondary end points. In patients $\geq 80$ years of age, there was a $34 \%$ reduction in relative risk of the primary end point with atorvastatin compared with placebo (HR 0.66, 95\% CI 0.57-1.00, $\mathrm{p}=0.05$ ).

Together, these studies demonstrated that high risk elderly individuals with stable coronary artery disease (SAGE, TNT, IDEAL) as well as those with recent acute events (PROVE IT, MIRACL) benefit from lipid lowering with statins. The improvement in clinical outcomes was at least similar to, if not greater than, that seen with middle-aged individuals. They also suggested that a lower LDL-C goal was associated with a better outcome. The REVERSAL trial proved that even within a short duration of 18 months, progression of atherosclerosis could be measurably reduced with intensive atorvastatin therapy. Use of atorvastatin is, therefore, reasonable and justified for the purpose of secondary prevention in elderly patients.

\section{Primary prevention trials with atorvastatin}

Compared with secondary prevention studies, the data regarding the use of statin therapy for the primary prevention of CHD in high-risk elderly patients are somewhat limited. Efficacy data from primary prevention trials using atorvastatin are presented in Table 2.

The Collaborative Atorvastatin Diabetes Study (CARDS) was a randomized placebo-controlled trial investigating atorvastatin $10 \mathrm{mg} / \mathrm{d}$ for primary prevention of CHD in 2838 patients ( 1129 patients $\geq 65$ years) with type 2 diabetes with LDL-C $\leq 160 \mathrm{mg} / \mathrm{dL}$, a fasting triglyceride $\leq 600 \mathrm{mg} / \mathrm{dL}$ and at least one of the following: retinopathy, albuminuria, current smoking, or hypertension (Colhoun et al 2004). Median duration of follow-up was 3.9 years as the trial was terminated 2 years earlier than planned because a prespecified early stopping rule for efficacy had been met. A 37\% reduction in incidence of major cardiovascular events was seen with atorvastatin (HR 0.63, 95\% CI 0.48-0.83, p = 0.001). When assessed separately, acute CHD events were reduced by $36 \%$ (HR 0.64, 95\% CI 0.45-0.91), coronary revascularizations by $31 \%$ (HR $0.69,95 \%$ CI $0.41-1.16$ ) and rate of stroke by $48 \%$ (HR 0.52, 95\% CI 0.31-0.89) (all p=0.001). A subsequent analysis comparing patients aged $65-75$ years with younger patients revealed that atorvastatin treatment resulted in a $38 \%$ $\mathrm{RR}$ reduction $(95 \% \mathrm{CI}-58$ to $-8, \mathrm{p}=0.017)$ of first major cardiovascular event in older patients similar to the $37 \%$ reduction ( $95 \% \mathrm{CI}-57$ to $-7, \mathrm{p}=0.019)$ seen in younger patients (Neil et al 2006). There was, however, a greater reduction in the absolute risk of cardiovascular events in older patients (3.9 vs $2.7 \%$ ) reflecting their higher absolute risk, and the NNT to avoid one event over 4 years was lower in the older group (21 vs 33, respectively).

The Anglo-Scandinavian Cardiac Outcomes Trial-Lipid Lowering Arm (ASCOT-LLA) was also designed to study lipid lowering in the primary prevention of CHD, in hypertensive patients who were not conventionally deemed dyslipidemic (Sever et al 2003). In this study, 10,305 hypertensive patients (6570 patients $>60$ years) without established CHD with nonfasting total cholesterol concentrations $\leq 251 \mathrm{mg} / \mathrm{dL}$ and $\geq 3$ cardiovascular risk factors were randomly assigned to receive atorvastatin $10 \mathrm{mg}$ or placebo in addition to matched antihypertensive treatment. Follow-up was planned for 5 years; however this trial was also stopped prematurely after a median of 3.3 years because of significant reduction in the primary endpoint of nonfatal $\mathrm{MI}$ and fatal CHD in the atorvastatin group compared with placebo (HR 0.64, 95\% CI $0.50-0.83, p=0.0005)$. This impact of atorvastatin on the primary endpoint was similar in the older subgroup of patients (HR 0.64, 95\% CI 0.47-0.86, $\mathrm{p}=0.0027$ ). Total cardiovascular events (HR 0.79, 95\% CI 0.69-0.90, p=0.0005) and total coronary events (HR $0.71,95 \%$ CI $0.59-0.86$, 


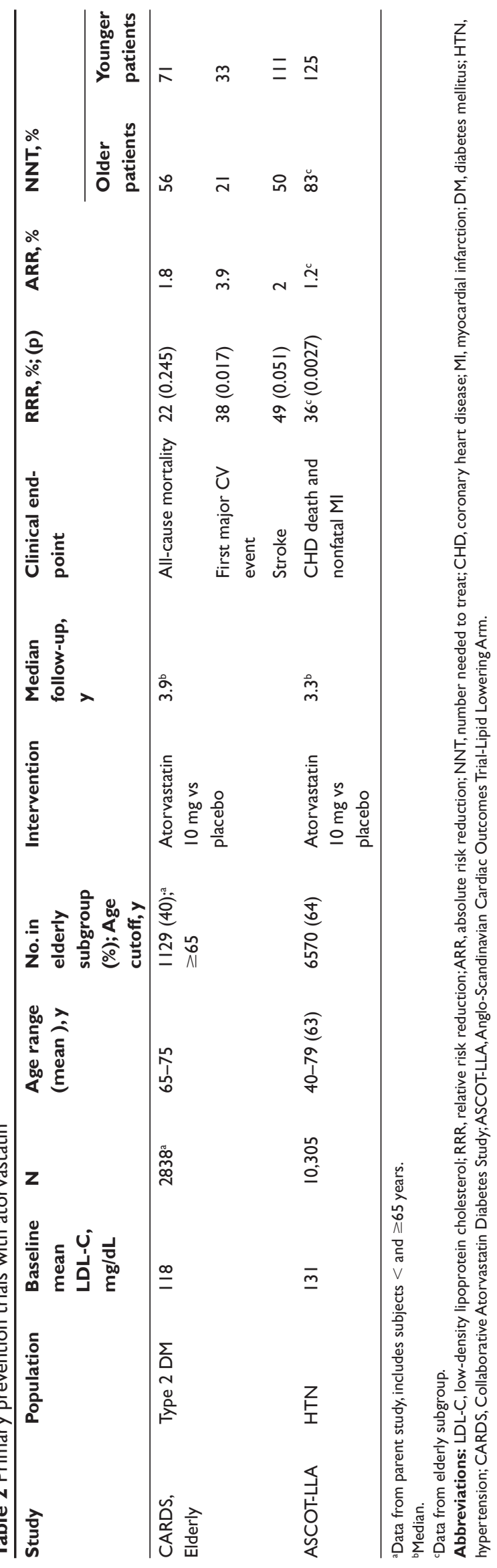

$\mathrm{p}=0.0005$ ) were also significantly lowered. A $27 \%$ reduction was seen in incidence of fatal and non-fatal stroke in atorvastatin-treated patients (HR 0.73, 95\% CI 0.56-0.96, $\mathrm{p}=0.024)$. Stroke prevention was similar for patients $>70$ years and $\leq 70$ years ( $31 \%$ vs $24 \%$ reduction). As in CARDS, to prevent the primary endpoint, a lower number of elderly patients needed to be treated in comparison to younger patients ( 83 vs 125 , respectively).

\section{Other trials and meta-analyses}

Table 3 shows data from other major trials that used a statin other than atorvastatin and included elderly participants. The Prospective Study of Pravastatin in the Elderly at Risk (PROSPER) deserves special mention, as it was the first study of lipid-lowering medication specifically among elderly patients. 5804 men and women aged 70-82 years with a history of or risk factors for vascular disease were randomized to pravastatin $40 \mathrm{mg} /$ day or placebo (Shepherd et al 2002). During a mean follow-up of only 3.2 years, pravastatin treatment was associated with a significantly reduced risk of the primary end point (composite of coronary death, nonfatal MI and fatal or nonfatal stroke) compared to placebo (HR 0.85 , 95\% CI 0.74-0.97, $\mathrm{p}=0.014)$. Stroke risk was unaffected by therapy, but pravastatin was associated with a lower rate of transient ischemic attacks (HR 0.75, 95 CI 0.55-1.00, $\mathrm{p}=0.051)$ and significantly reduced risk of coronary death and nonfatal MI (HR 0.81, 95\% CI 0.69-0.94, p = 0.006).

The Scandinavian Simvastatin Survival Study (4S) included 1021 patients $\geq 65$ years of age with established CHD and hypercholesterolemia (213 to $309 \mathrm{mg} / \mathrm{dL}$ ) (Miettinen et al 1997). Similar reductions in serum lipids were observed among elderly and younger individuals with simvastatin (20-40 mg/d). Among the elderly, treatment with simvastatin was associated with reductions in all-cause mortality (HR $0.66,95 \%$ CI $0.48-0.90, \mathrm{p}=0.009$ ), CHD mortality (HR $0.57,95 \%$ CI $0.39-0.83, \mathrm{p}=0.003$ ), major coronary events (HR 0.66, 95\% CI 0.52-0.84, p < 0.001) and nonfatal MI (HR 0.67, 95\% CI 0.51-0.88, $\mathrm{p}=0.004$ ). For each of these, the NNT was lower in elderly patients (see Table 3). More than twice the number of deaths could be prevented by simvastatin therapy among the elderly compared with the younger subgroup (61.5 vs 25.5 [all-cause] and 60.2 vs 28.1 [CHD] per 1000 patients).

The Cholesterol and Recurrent Events (CARE) trial evaluated the effect of pravastatin (40 mg/day) on 1283 patients aged 65-75 years who had a history of MI and had total cholesterol levels in the average range $(<240 \mathrm{mg} / \mathrm{dL})$ (Lewis et al 1998). Major coronary events, coronary deaths 


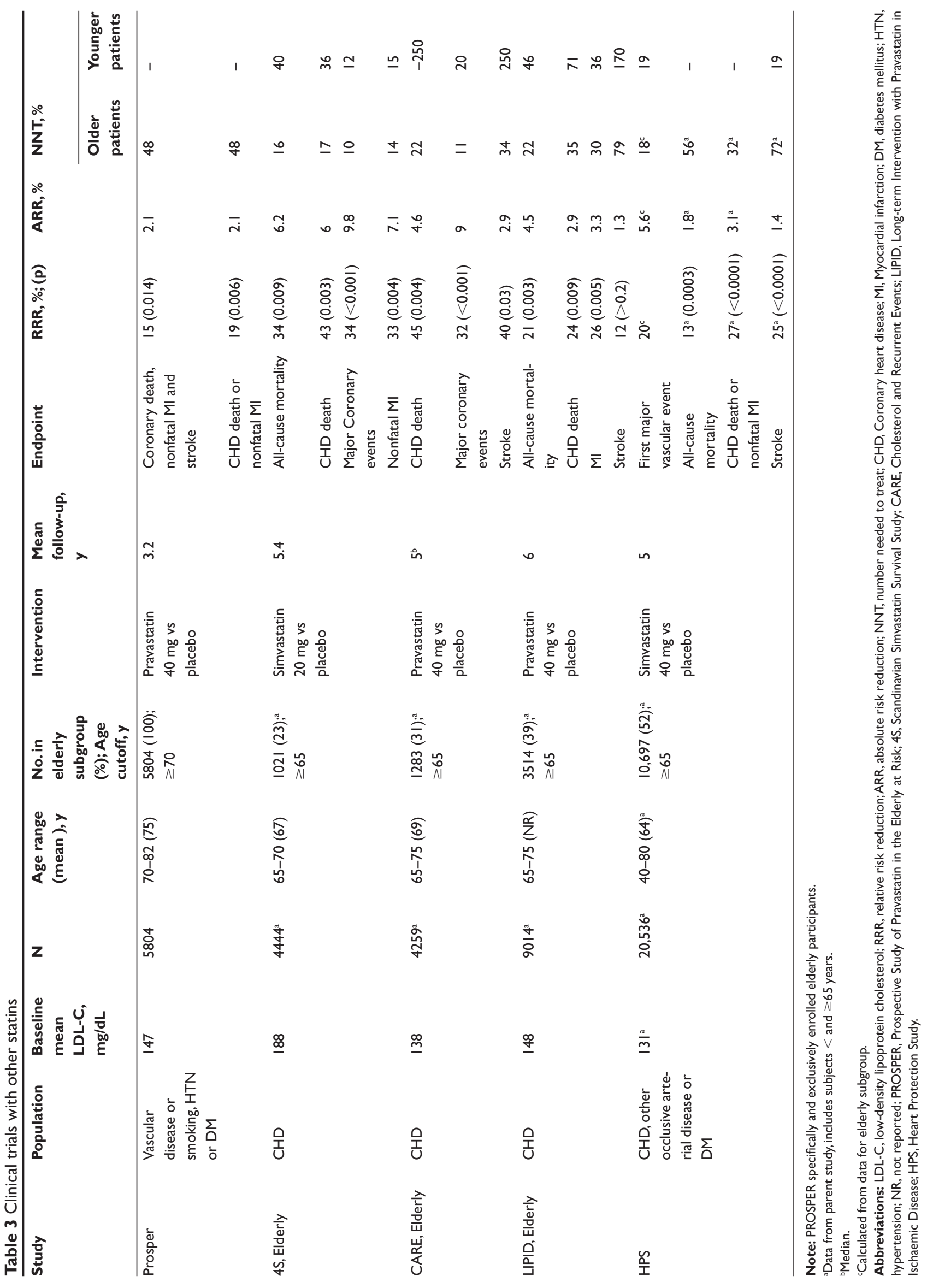


and strokes were all significantly reduced by $32 \%(95 \%$ CI $15 \%-46 \%, p=0.001), 45 \%$ (95\% CI 18\%-63\%, $\mathrm{p}=0.004)$, and 40\% (95\% CI 4\%-62\%, p = 0.03), respectively. Compared to younger patients, a lower number of elderly people needed statin therapy to avoid these cardiovascular outcomes (see Table 3 ).

The Long-Term Intervention with Pravastatin in Ischaemic Disease (LIPID) trial included 3514 patients aged 65 and 75 years who had a prior infarction or unstable angina in addition to average or moderately elevated cholesterol levels (155-271 mg/dL) (Hunt et al 2001). Pravastatin (40 mg/day) led to reductions in all-cause mortality (HR 0.79, 95\% CI $0.68-0.93, \mathrm{p}=0.003$ ), CHD mortality (HR 0.76, 95\% CI $0.62-0.93, \mathrm{p}=0.009)$, MI (HR 0.74, 95\% CI 0.60-0.91, $\mathrm{p}=0.005$ ) and stroke (HR 0.88, 95\% CI 0.68-1.15, p > 0.2) in the group $>65$ years of age. Although the relative effect of pravastatin therapy was similar in older and younger patients, the absolute risk reduction was greater and the NNT was lower in the elderly (see Table 3).

The Heart Protection Study is the largest statin study to be done till date. It recruited 20,536 high-risk individuals (5806 patients $\geq 70$ years) with cardiovascular disease, diabetes or treated hypertension and evaluated the effects of simvastatin $40 \mathrm{mg} /$ day (HPSCG 2002). There was a $24 \%$ reduction $(95 \%$ CI $19 \%-28 \%, \mathrm{p}<0.0001)$ in first major vascular events along with significant reductions in all-cause mortality and CHD mortality. The proportional reduction in event rate was consistent irrespective of the age of the participants. Even among the 1263 individuals 75-80 years of age, major vascular events were significantly reduced with simvastatin compared to placebo (23.1\% vs $32.3 \%, \mathrm{p}=0.0002)$.

A prospective meta-analysis of data from 90,056 individuals in 14 randomized trials of statins was done by the Cholesterol Treatment Trialists' (CTT) Collaborators (Baigent et al 2005). The statin group included 45,054 cardiovascular events, of which $16.6 \%$ were in subjects aged $\geq 65$ years. The placebo group included 45,002 events of which $20.3 \%$ were in this age group. Subgroup analysis in patients aged $\geq 65$ years revealed a $19 \%$ reduction in major coronary events (RR $0.81,95 \%$ CI $0.76-0.88, \mathrm{p}=0.01)$ and major vascular events (RR $0.81,95 \%$ CI $0.77-0.86, \mathrm{p}=0.1$ ). For those aged $\geq 75$ years, an $18 \%$ reduction was seen in major coronary events (RR 0.82, 99\% CI 0.70-0.96, p = 0.002) and major vascular events (RR 0.82, 99\% CI 0.72-0.93, p < 0.001). Another meta-analysis evaluated data on 51,351 patients from 18 randomized, placebo-controlled statin trials to determine efficacy of statin monotherapy in patients $\geq 60$ years of age (Roberts et al 2007). The statin group showed a significant
$15 \%$ reduction in all-cause mortality (RR $0.85,95 \% \mathrm{CI}$ $0.78-0.93, \mathrm{p}=0.001), 23 \%$ reduction in CHD deaths (RR $0.77,95 \%$ CI $0.71-0.85, \mathrm{p}<0.001), 26 \%$ reduction in fatal or nonfatal MI (RR 0.74, 95\% CI 0.70-0.78, p < 0.001) and $24 \%$ reduction in fatal or nonfatal stroke (RR $0.76,95 \% \mathrm{CI}$ $0.65-0.90, \mathrm{p}=0.001)$.

\section{Safety and tolerability Liver function and creatine kinase (CK)}

Statins are generally well tolerated and adverse events are usually mild and transient, even among elderly patients. In their meta-analysis among patients $\geq 60$ years of age, Roberts et al found musculoskeletal symptoms along with abnormalities in CK and liver enzymes to be the most commonly reported adverse events (Roberts et al 2007). Rates of transaminase elevations $>3$ times the upper limit of normal (ULN) or CK elevations $>10$ times ULN were similar in the statin and placebo groups as were the rates of withdrawal from study due to adverse events. In another meta-analysis of 23 randomized statin treatment arms with 309,506 person-years of follow-up, rates of elevated liver enzymes increased significantly with increased statin doses for any 10\% LDL-C reduction (Alsheikh-Ali et al 2007). The rate of liver enzyme elevation with atorvastatin $80 \mathrm{mg} / \mathrm{d}$ was 4 times greater compared with atorvastatin $10 \mathrm{mg} / \mathrm{d}$ $(\mathrm{p}<0.001)$. Thus, hepatotoxic effects were related to the drug and dose used, rather than the magnitude of LDL-C lowering. Table 4 summarizes the effects of statins on liver enzymes, CK rise as well as rates of rhabdomyolysis from major clinical trials.

PROSPER (Shepherd et al 2002) and SAGE (Deedwania et al 2007), the only 2 trials which focused exclusively on the elderly, had follow-ups of 3.2 years and 1 year, respectively. Serious adverse events were similar in the two treatment arms in both trials except that liver function test abnormalities were more frequent in the atorvastatin group than in the pravastatin group (4.3 versus $0.2 \%, \mathrm{p}<0.001$ ) in SAGE. However, liver enzyme levels returned to normal for all patients on repeat testing during follow-up or on discontinuation of study medication. There were no cases of rhabdomyolysis in either study.

Data from other large-scale trials using atorvastatin further support these findings. In the ASCOT (Sever et al 2003) and CARDS trials (Colhoun et al 2004) where follow-up was relatively short (median 3.3 and 3.9 years, respectively), there were no significant differences in the incidence of serious adverse events and liver enzyme abnormalities between the atorvastatin (10 mg/day)- and placebo-treated groups. One 


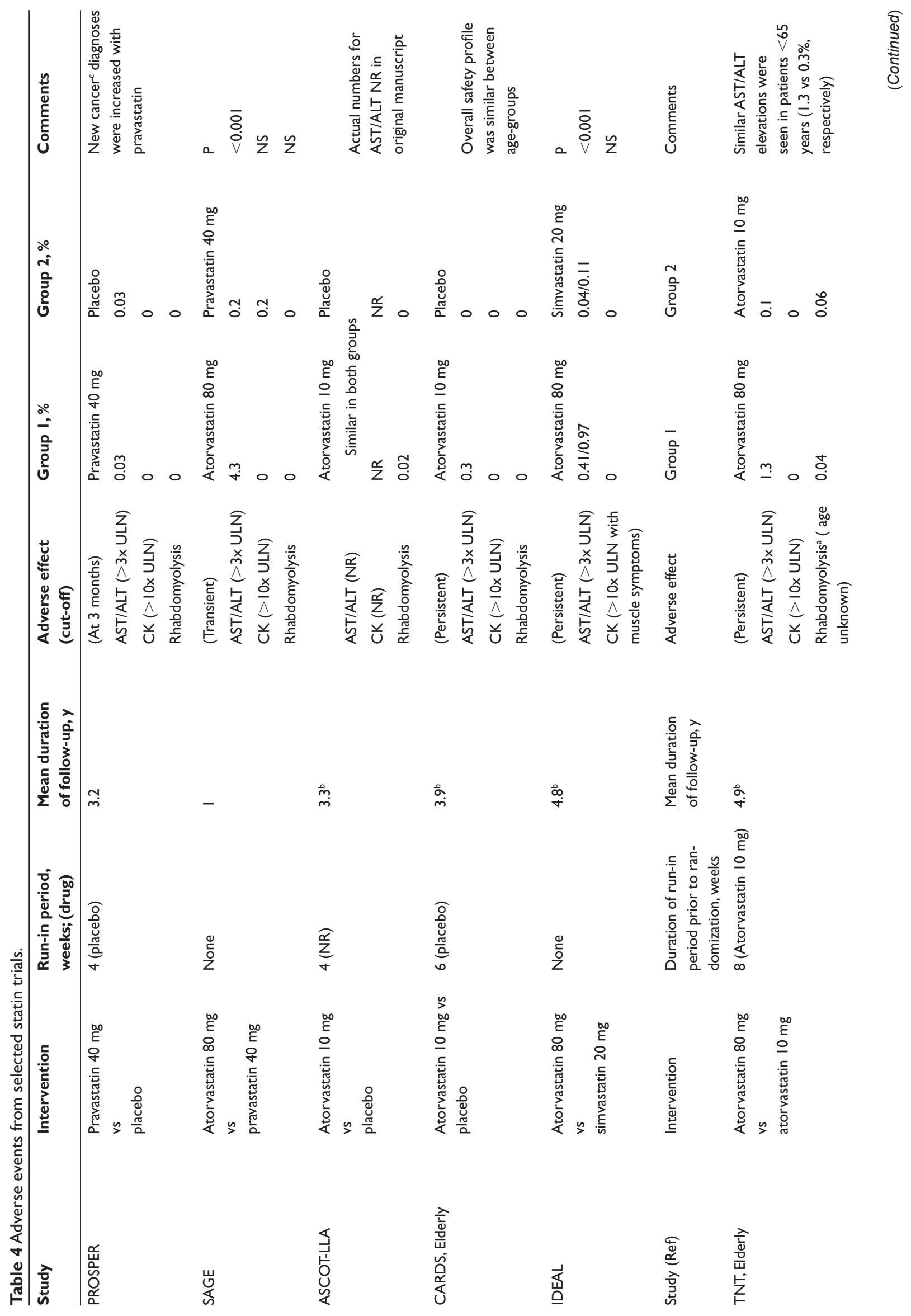


case of rhabdomyolysis was reported in a man with very high alcohol intake and a recent febrile illness in ASCOT; no cases occurred in CARDS. Post hoc analysis of the CARDS trial concluded that atorvastatin was equally safe and well tolerated among patients aged 65-75 years (Neil et al 2006). In PROVE IT, with 2 years follow-up, there was no difference between elderly and younger patients in the incidence of elevated liver enzymes ( 2.3 vs. $2.2 \%, \mathrm{p}=0.8$ ) as well as the rates of $\mathrm{CK}$ rise ( 1.1 vs. $1.3 \%, \mathrm{p}=0.6$ ) (Ray et al 2006). Compared with younger patients, the elderly did not have any increased rates of discontinuation of study drug for myalgia or CK rise or for any other side effect. As with younger patients, transient elevations in liver enzymes were more likely with atorvastatin $(80 \mathrm{mg} / \mathrm{d})$ compared with pravastatin $(40 \mathrm{mg} / \mathrm{d})$ among the elderly (4.8 vs $0 \%$, $\mathrm{p}<0.0001)$. Similar rates of CK rise were seen with both regimens in older subjects $(1.1 \%, p=0.9)$. There were no cases of rhabdomyolysis.

In contrast, in studies with longer follow-up of approximately 5 years, differences did occur. In IDEAL, high-dose atorvastatin $(80 \mathrm{mg} /$ day $)$ was associated with increased transaminase elevations $(0.97 \%$ vs $0.11 \%$, p $<0.001)$, myalgias $(2.2 \%$ vs $1.1 \%, \mathrm{p}<0.001)$ and more nonserious adverse events resulting in drug discontinuation $(9.6 \%$ vs $4.2 \%, \mathrm{p}<0.001)$ compared to simvastatin $(40 \mathrm{mg} /$ day $)$ after 4.8 years of follow-up (Pedersen et al 2005). The authors acknowledged the possibility of reporting bias given the open-label design of this trial. There were $2(0.05 \%)$ cases of rhabdomyolysis with atorvastatin and $3(0.07 \%)$ with simvastatin. In TNT, during a median follow-up of 4.9 years, a greater number of patients receiving high-dose atorvastatin had persistent transaminase elevations (1.2\% vs $0.2 \%, p<0.001)$ (LaRosa et al 2005). There were no subjects with persistent CK elevation. Five cases of rhabdomyolysis were reported in the entire study cohort. All had potential confounding factors and were not believed to be related to the study drug. Rates of persistent liver enzyme elevations with atorvastatin $80 \mathrm{mg}$ /day compared to atorvastatin $10 \mathrm{mg} / \mathrm{d}$ were $1.3 \%$ vs $0.3 \%$ for patients $<65$ years and 1.3 vs $0.1 \%$ for subjects $\geq 65$ years of age (Wenger et al 2007). The differences in adverse event profiles between the treatment groups among the elderly were similar to the entire study sample.

\section{Cognitive function}

Effect on cognitive function is an area of special concern with regard to statin use in the elderly. Statins have been shown to cause minor decrements in cognitive function in 
small studies, manifested as a lack of improvement between baseline and post-treatment assessments rather than an absolute decline in performance (Muldoon et al 2000; Muldoon et al 2004). In the much larger HPS (HPSCG 2002) and PROSPER (Shepherd et al 2002) trials, statins did not have any deleterious effects on cognition.

\section{Cancer}

In PROSPER, new cancer diagnoses were more frequent in patients receiving pravastatin than those receiving placebo (Shepherd et al 2002). In one recent meta-analysis, cancer rates were significantly greater in the statin group (RR 1.16, 95\% CI 1.01-1.22, $\mathrm{p}=0.04, \mathrm{p}$ for heterogeneity $=0.25$ ) in subjects aged 65 years and older (Roberts et al 2007). However, this was based on data from 3 trials only and the authors acknowledged the need for more consistent reporting of cancer rates and longer follow-up periods to further study the role of statins among the elderly in this regard. In their larger meta-analysis, Alsheikh-Ali et al demonstrated a significant inverse relationship between rates of newly diagnosed cancer and achieved LDL-C levels (Alsheikh-Ali et al 2007). Several meta-analyses of other statin trials, including one by the PROSPER authors, have shown no increase in cancer risk (Baigent et al 2005; Dale et al 2006).

It is important to note that safety data in clinical trials are obtained from a carefully selected and closely monitored study population. Subjects with signs of statin intolerance (eg, muscular complaints, liver dysfunction) either in the past or during the initial run-in phase are usually excluded from these studies, as are patients with similar problems at baseline. Patients in clinical practice generally have more coexisting conditions than study patients, and are usually on several concomitant medications which may affect atorvastatin metabolism. Also, the limits of acceptable CK and transaminase elevations in these studies are certainly higher than most physicians would be comfortable with in routine practice. Thus, while lower doses of atorvastatin are generally safe, it is possible that elderly patients may not tolerate the high-dose as well as study subjects.

\section{Adherence}

Despite their apparent benefits, adherence to statin therapy remains low among older patients (Benner et al 2002; Jackevicius et al 2002; Benner et al 2005). A retrospective cohort study of 34,501 patients $\geq 65$ years of age measured proportion of days (PDC) covered by statins in each quarter during the first year of therapy and every 6 months thereafter, in routine care settings (Benner et al 2002). Compliance with statin therapy decreased markedly with time, with the largest decline observed within the first 6 months of treatment after which mean PDC fell to $56 \%$. Only $43 \%$ of patients were adherent (defined as PDC $\geq 80 \%$ ) to statin therapy at the end of this period. After 5 years, only 1 in 4 patients were still adherent to their medications, a number far less than that reported in clinical trials. Patients aged $\geq 75$ years had $19 \%$ greater odds of poor persistence. Patients with more severe baseline CHD had better adherence. Interestingly, this study also found that patients who had an MI while on statins were less likely to continue statin use following the event. Other studies have shown that elderly patients with recent ACS are more adherent than those taking statins for stable CHD and primary prevention (Jackevicius et al 2002). It has also been suggested that greater reductions in LDL-C during the first three months of statin therapy is associated with improved adherence (Benner et al 2005). In many clinical trials, patients who seem unwilling to comply with long-term study medication during the initial run-in period are typically excluded from the study to decrease the drop-out rate and improve statistical sensitivity. Therefore, results from these trials may be less applicable to the general population because only "compliers" are included in the actual trial.

\section{Drug interactions}

Elderly patients are frequently treated with multiple medications and so are at increased risk for complications of drug interactions. Since statins are highly selective inhibitors of HMG-CoA reductase, drug-drug interactions are mainly pharmacokinetic, rather than pharmacodynamic. Atorvastatin undergoes microsomal metabolism in the liver by the cytochrome P-450 3A4 (CYP3A4) isoenzyme. This isoenzyme also metabolizes about $60 \%$ of all drugs used in clinical practice today, increasing the risk of interactions (Zhou et al 2005). Antifungal agents (eg, ketoconazole and other azoles), antibiotics (eg, clarithromycin, erythromycin and isoniazid), antiretrovirals (eg, ritonavir and delavirdine), anticancer drugs (eg, tamoxifen and irinotecan), sex steroids and estrogen receptor modulators (eg, gestodene and raloxifene), herbal constituents (eg, bergamottin in grapefruit juice and glabridin in licorice) and other cardiovascular medications (eg, hydralazine, verapamil, and diltiazem) inhibit this isoenzyme, increase the plasma levels of statins, and may lead to statin-related adverse effects (eg, myotoxicity). A recent review based on 152 published reports and notifications to the US Food and Drug Administration (FDA) of cases of statin related rhabdomyolysis showed that these drugs were coadministered in 60\% of the cases (Law et al 2006). An 
estimated $19 \%$ of cases occurred in patients taking statins with fibrates, principally gemfibrozil. Fibrates are not CYP3A4 inhibitors and influence the metabolic clearance of statins via inhibitory effects on glucuronidation and/or non-CYP3A4-mediated oxidative pathways (Prueksaritanont et al 2002). In elderly patients, further caution is warranted in view of the age-related decline in hepatic drug metabolism by the cytochrome system (Cusack 2004).

\section{Cost effectiveness}

Ward et al reviewed 31 randomized statin trials to determine the costs associated with statin treatment taking into account the CHD outcomes (Ward et al 2007). Based on a threshold of $£ 20,000$ per quality adjusted life year (QALY), the authors concluded that statin therapy was cost-effective in secondary prevention of CHD in all patients aged 45-85 years. In primary prevention, cost-effectiveness varied according to age and level of risk. At an annual CHD risk of 3\%, between ages 45 and 85 years cost per QALY ranged from $£ 9500$ to $£ 36,800$ for men and $£ 13,700$ to $£ 47,400$ for women. At a lower risk of $0.5 \%$, cost per QALY was $£ 105,200$ and $£ 110,600$ for men and women at 85 years of age, respectively. They also noted that the cost-effectiveness was significantly enhanced if stroke and transient ischemic attack (TIA) outcomes were taken into account, particularly among the elderly where the benefits of avoided stroke and TIA events are greater. Atorvastatin has been shown to be more cost effective compared to fluvastatin, lovastatin, pravastatin, and simvastatin in various analyses (Huse et al 1998; Elliott et al 1999). Rosuvastatin is a recently introduced potent statin that was found to be more cost-effective than atorvastatin based on cost per $1 \%$ reduction in LDL-C and cost per patient treated to their LDL-C goal in the Statin Therapies for Elevated Lipid Levels Compared Across Doses to Rosuvastatin (STELLAR) trial (Miller et al 2005). However, currently there is no direct trial evidence examining the effect of rosuvastatin on clinical endpoints of $\mathrm{CHD}$, whereas atorvastatin has been widely tested in this regard. Also, there is limited evidence on the long-term safety of rosuvastatin in large randomized trials.

\section{Alternate-day dosing}

Given the prolonged duration of $\mathrm{HMG}-\mathrm{CoA}$ reductase inhibition achieved with atorvastatin, many trials have been conducted to evaluate the efficacy of alternate-day dosing of this drug compared with the standard once-daily dosing. The Alternate Day Versus Daily Dosing of Atorvastatin Study (ADDAS) randomized 35 hypercholesterolemic patients to receive atorvastatin $10 \mathrm{mg}$ as initial dose every day or every other day (Matalka et al 2002). The dose was doubled if LDL-C goal was not reached at 6 and 12 weeks. At 12 weeks, LDL-C reduction was similar in both groups (35\% in the every-other-day group vs $38 \%$ in the every-day group, $\mathrm{p}=0.49)$, though the every-day group had greater LDL-C reductions at 6 weeks $(27 \%$ vs $38 \%, \mathrm{p}=0.01)$. The mean dose was $18 \mathrm{mg}$ ( $9 \mathrm{mg} /$ day) and $12 \mathrm{mg} /$ day in the alternate-day and once-daily groups, respectively $(p=0.001)$. The authors performed a monthly cost analysis based on the second phase of the study to calculate the cost of $1 \%$ LDL-C reduction per patient ( $\$ 1.22$ vs $\$ 1.71$ in the alternate-day and every-day groups, respectively). Using the average wholesale price, they calculated a 34\% saving in annual drug cost per patient for the alternate-day group (\$513 vs \$782). Another similar trial among 54 patients found no statistically significant differences between atorvastatin $10 \mathrm{mg}$ every day, $10 \mathrm{mg}$ every other day, and $20 \mathrm{mg}$ every other day for total, or a percentage, decrease in total cholesterol and LDL-C at 6 weeks compared to baseline (Jafari et al 2003). Several other studies have concluded that alternate-day dosing of atorvastatin is a safe, efficacious, and cost-effective alternative to daily dosing (Piamsomboon et al 2002; Juszczyk et al 2005; Ferrer-García et al 2006).

\section{Management strategies and place in therapy}

Table 5 highlights some of the key points discussed in this paper. Elderly patients are at high risk of heart disease and statin therapy has been proven to have a favorable effect on the cardiovascular outcome in these patients. In 2001, the

\section{Table 5 Key messages from this review}

- Elderly individuals are more likely to have heart disease, particularly subclinical atherosclerosis.

- Atorvastatin is the most potent statin with proven benefit in terms of improved clinical outcomes.

- Atorvastatin has been widely tested among older people, both with and without known coronary heart disease.

- Elderly patients benefit equally, if not more, with atorvastatin therapy compared to their younger counterparts.

- Atorvastatin therapy in these patients is cost-effective when considering cardiovascular outcomes and cost-savings from reduced hospitalization.

- Lower doses of statins are generally safe in the elderly population.

- Atorvastatin is also effective in an alternate dose regimen, which makes it particularly attractive for older patients having statin-related adverse effects.

- Therefore, the risk-benefit ratio for atorvastatin therapy remains favorable even in older individuals. 
Third report of the National Cholesterol Education Program (NCEP) Adult Treatment Panel recommended that persons older than 65 years of age should not be denied the benefits of LDL-lowering therapy (NCEP 2001). Based on data from HPS and PROSPER, these recommendations were updated in 2004 (Grundy et al 2004). The NCEP concluded that strong justification existed for LDL-lowering therapy in older persons with established CVD. For elderly patients without established CVD, the NCEP relied on additional data from PROSPER and ASCOT to recommend the use of clinical judgment in addition to the Framingham risk score for initiating lipid-lowering therapy. Such patients may have subclinical atherosclerosis which would make lipid lowering with statins beneficial. New data from the SAGE and PROVE-IT subanalysis support the use of aggressive lipid modification (LDL-C goal $<70 \mathrm{mg} / \mathrm{dL}$ ) in elderly patients at particularly high-risk, especially those with recent coronary events.

Atorvastatin is one of the more potent statins in terms of LDL-C lowering and has been shown to have several beneficial pleiotropic effects on underlying atherosclerosis over and above lipid lowering. It has been widely tested among the elderly in clinical trials as well as in real-life patients in clinical practice. The SAGE trial included patients as old as 85 years of age, suggesting that the benefits of atorvastatin can extend up to that age. Of all the statins proven to improve CHD outcomes, atorvastatin is the most cost-effective. Therapy in older CHD patients may be more cost-effective compared with their younger counterparts despite their shorter life expectancy. This is because higher baseline risk in older individuals allows greater cost savings from decreased rates of hospitalization resulting from preventive treatment (Tonkin et al 2006). The pharmacokinetic properties of atorvastatin make it suitable for every-other-day dosing, which can further enhance its cost-effectiveness.

Special efforts should be made to increase compliance to statin therapy among elderly patients, particularly in those with stable disease. Older patients may be more susceptible to adverse effects of these drugs. A careful medical history should be elicited prior to initiating statin therapy, with special emphasis on concomitant medications and medical illnesses which may make patients unsuitable for such therapy. Careful monitoring is required, even though most of the adverse effects are relatively minor and reversible. In clinical practice, many elderly patients may still be unable to reach their lipid goals due to statin-related symptoms or laboratory abnormalities. Such patients should be switched to an alternate-day regimen of atorvastatin since statin-related adverse effects may not be as prominent on an every-other-day dosing, thus, allowing these patients to achieve their LDL-C goals.

In conclusion, benefits of statin therapy far outweigh any safety concerns, especially among older CHD patients who may be otherwise healthy. By reducing morbidity related to acute coronary events, statins can enhance the quality of life and lead to a more productive old age. While extra caution is warranted with high-dose statin therapy, particularly in those with concomitant medical conditions such as chronic kidney or liver disease, increased chronological age alone should not exclude any patient from receiving the benefits of such treatment. Atorvastatin has been proven to improve clinical outcomes, even when compared to other statins in large randomized clinical trials, and is generally well tolerated in the elderly population. It is therefore a suitable choice when considering statin therapy in this group of patients.

\section{References}

Alsheikh-Ali AA, Maddukuri PV, Han H, et al. 2007. Effect of the magnitude of lipid lowering on risk of elevated liver enzymes, rhabdomyolysis, and cancer: insights from large randomized statin trials. $J$ Am Coll Cardiol, 50:409-18.

Assmann G, Cullen P, Schulte H. 1998. The Münster Heart Study (PROCAM). Results of follow-up at eight years. Eur Heart J, 19:A2-A11.

Avezum A, Makdisse M, Spencer F, et al. 2005. Impact of age on management and outcome of acute coronary syndrome: observations from the Global Registry of Acute Coronary Events (GRACE). Am Heart J, 149:67-73.

Baigent C, Keech A, Kearney PM, et al.; Cholesterol Treatment Trialists Collaborators. 2005. Efficacy and safety of cholesterol-lowering treatment: prospective meta-analysis of data from 90,056 participants. Lancet, 366:1267-78.

Bandyopadhyay S, Bayer AJ, O’Mahony MS. 2001. Age and gender bias in statin trials. QJM, 94:127-32.

Benfante R, Reed D. 1990. Is elevated serum cholesterol level a risk factor for coronary heart disease in the elderly? JAMA, 263:393-96.

Benner JS, Glynn RJ, Mogun H, et al. 2002. Long-term persistence in use of statin therapy in elderly patients. JAMA, 288:455-61.

Benner JS, Pollack MF, Smith TW, et al. 2005. Association between shortterm effectiveness of statins and long-term adherence to lipid-lowering therapy. Am J Health Syst Pharm, 62:1468-75.

Bonow RO, Smaha LA, Smith SC Jr, et al. 2002. World Heart Day 2002: the international burden of cardiovascular disease: responding to the emerging global epidemic. Circulation, 106:1602-5.

Brown MS, Goldstein JL. 1986. A receptor-mediated pathway for cholesterol homeostasis. Science, 232:34-47.

Cannon CP, Braunwald E, McCabe CH, et al.; Pravastatin or Atorvastatin Evaluation and Infection Therapy-Thrombolysis in Myocardial Infarction 22 Investigators (PROVE IT-TIMI 22). 2004. Intensive versus moderate lipid lowering with statins after acute coronarysyndromes. N Engl J Med, 350:1495-504.

Castelli WP, Wilson PW, Levy D, et al. 1989. Cardiovascular risk factors in the elderly. Am J Cardiol, 63:12H-19H.

Colhoun HM, Betteridge DJ, Durrington PN, et al. 2004. Primary prevention of cardiovascular disease with atorvastatin in type 2 diabetes in the Collaborative Atorvastatin Diabetes Study (CARDS): multicentre randomised placebo-controlled trial. Lancet, 364:685-96.

Conde K, Vergara-Jimenez M, Krause BR, et al. 1996. Hypocholesterolemic actions of atorvastatin are associated with alterations on hepatic cholesterol metabolism and lipoprotein composition in the guinea pig. J Lipid Res, 37:2372-82. 
Cournot M, Cambou JP, Quentzel S, et al. 2006. Key factors associated with the under-prescription of statins in elderly coronary heart disease patients: results from the ELIAGE and ELICOUR surveys. Int J Cardiol, 111:12-18.

Cusack BJ. 2004. Pharmacokinetics in older persons. Am J Geriatr Pharmacother, 2:274-302.

Dale KM, Coleman CI, Henyan NN, et al. 2006. Statins and cancer risk: a meta-analysis. JAMA, 295:74-80.

Deedwania P, Stone PH, Bairey Merz CN, et al. 2007. Effects of intensive versus moderate lipid-lowering therapy on myocardial ischemia in older patients with coronary heart disease: results of the Study Assessing Goals in the Elderly (SAGE). Circulation, 115:700-7.

Downs JR, Clearfield M, Weis S, et al. for the AFCAPS/TexCAPS Research Group. 1998. Primary prevention of acute coronary events with lovastatin in men and women with average cholesterol levels: Results of AFCAPS/TexCAPS. Air Force/Texas Coronary Atherosclerosis Prevention Study. JAMA, 279:1615-22.

Elliott WJ, Weir DR. 1999. Comparative cost-effectiveness of HMG-CoA reductase inhibitors in secondary prevention of acute myocardial infarction. Am J Health Syst Pharm, 56:1726-32.

Ferrer-García JC, Pérez-Silvestre J, Martínez-Mir I, et al. 2006. Alternateday dosing of atorvastatin: effects in treating type 2 diabetic patients with dyslipidaemia. Acta Diabetol, 43:75-8.

Fonarow GC, French WJ, Parsons LS, et al. 2001. Use of lipid-lowering medications at discharge in patients with acute myocardial infarction: data from the National Registry of Myocardial Infarction 3.Circulation, 103:38-44.

Ford ES, Giles WH, Mokdad AH. 2004. Increasing prevalence of the metabolic syndrome among US Adults. Diabetes Care, 27:2444-9.

Frost PH, Davis BR, Burlando AJ, et al. for the Systolic Hypertension in the Elderly Research Group. 1996. Serum lipids and incidence of coronary heart disease. Findings from the Systolic Hypertension in the Elderly Program (SHEP). Circulation, 94:2381-8.

Ghosh S, Ziesmer V, Aronow WS. 2002. Underutilization of aspirin, beta blockers, angiotensin-converting enzyme inhibitors, and lipid-lowering drugs and overutilization of calcium channel blockers in older persons with coronary artery disease in an academic nursing home. $J$ Gerontol A Biol Sci Med Sci, 57:M398-400.

Grundy SM, Cleeman JI, Bairey Merz CN, et al. 2004. Implications of recent clinical trials for the National Cholesterol Education Program Adult Treatment Panel III guidelines. Circulation, 110:227-39.

Houterman S, Verschuren WM, Hofman A, et al. 1999. Serum cholesterol is a risk factor for myocardial infarction in elderly men and women: the Rotterdam Study. J Intern Med, 246:25-33.

[HPSCG] Heart Protection Study Collaborative Group. 2002. MRC/BHF Heart Protection Study of cholesterol lowering with simvastatin in 20,536 high-risk individuals: a randomised placebo-controlled trial. Lancet, 360:7-22.

Hunt D, Young P, Simes J, et al. 2001. Benefits of pravastatin on cardiovascular events and mortality in older patients with coronary heart disease are equal to or exceed those seen in younger patients: Results from the LIPID trial. Ann Intern Med, 134:931-40.

Huse DM, Russell MW, Miller JD, et al. 1998. Cost-effectiveness of statins. Am J Cardiol, 82:1357-63.

Jackevicius CA, Mamdani M, Tu JV. 2002. Adherence with statin therapy in elderly patients with and without acute coronary syndromes. JAMA, 288:462-7.

Jafari M, Ebrahimi R, Ahmadi-Kashani M, et al. 2003. Efficacy of alternateday dosing versus daily dosing of atorvastatin. J Cardiovasc Pharmacol Ther, 8:123-6.

Jialal I, Stein D, Balis D, et al. 2001. Effect of hydroxymethyl glutaryl coenzyme A reductase inhibitor therapy on high sensitive C-reactive protein levels. Circulation, 103:1933-5.

Juszczyk MA, Seip RL, Thompson PD. 2005. Decreasing LDL cholesterol and medication cost with every-other-day statin therapy. Prev Cardiol, 8:197-9.

Kronmal RA, Cain KC, Ye Z, et al.1993. Total serum cholesterol levels and mortality risk as a function of age. A report based on the Framingham data. Arch Intern med, 153:1065-73.
LaRosa JC, Grundy SM, Waters DD, et al.; Treating to New Targets (TNT) Investigators. 2005. Intensive lipid lowering with atorvastatin in patients with stable coronary disease. $N$ Engl J Med, 352:1425-35.

Laufs U, Wassmann S, Hilgers S, et al. 2001. Rapid effects on vascular function after initiation and withdrawal of atorvastatin in healthy, noncholesterolemic men. Am J Cardiol, 88:1306-7.

Law M, Rudnicka AR. 2006. Statin safety: a systematic review. Am $J$ Cardiol, 97:52C-60C

Lea AP, McTavish D. 1997. Atorvastatin: a review of its pharmacology and therapeutic potential in the management of hyperlipidemias. Drugs, 53:828-47.

Lewis SJ, Moye LA, Sacks FM, et al. for the CARE Investigators. 1998. Effect of pravastatin on cardiovascular events in older patients with myocardial infarction and cholesterol levels in the average range. Ann Intern Med, 129:681-9.

LIPID Study Group. 1998. The Long-Term Intervention with Pravastatin in Ischaemic Disease (LIPID) Study Group. 1998. Prevention of cardiovascular events and death with pravastatin in patients with coronary heart disease and a broad range of initial cholesterol levels. N Engl J Med, 339:1349-57.

Lloyd-Jones DM, Larson MG, Beiser A, et al. 1999. Lifetime risk of developing coronary heart disease. Lancet, 353:89-92.

Marchesi S, Lupattelli G, Siepi D, et al. 2000. Short-term atorvastatin treatment improves endothelial function in hypercholesterolemic women. J Cardiovasc Pharmacol, 36:617-21.

Martinez-Gonzalez J, Badimon L. 2007. Influence of statin use on endothelial function: from bench to clinics. Curr Pharm Des, 13:1771-86.

Matalka MS, Ravnan MC, Deedwania PC. 2002. Is alternate daily dose of atorvastatin effective in treating patients with hyperlipidemia? The Alternate Day Versus Daily Dosing of Atorvastatin Study (ADDAS). Am Heart J, 144:674-7.

McCarey DW, McInnes IB, Madhok R, et al. 2004. Trial of Atorvastatin in Rheumatoid Arthritis (TARA): double-blind, randomised placebocontrolled trial. Lancet, 363:2015-21.

Miettinen TA, Pyorala K, Olsson AG, et al. for the Scandinavian Simvastatin Study Group. 1997. Cholesterol-lowering therapy in women and elderly patients with myocardial infarction or angina pectoris: Findings from the Scandinavian Simvastatin Survival Study (4S). Circulation, 96:4211-8.

Miller PS, Smith DG, Jones P. 2005. Cost effectiveness of rosuvastatin in treating patients to low-density lipoprotein cholesterol goals compared with atorvastatin, pravastatin, and simvastatin (a US Analysis of the STELLAR Trial). Am J Cardiol, 95:1314-9.

Miniño AM, Heron MP, Murphy SL, et al. 2007. Deaths: Final Data for 2004. Natl Vital Stat Rep, 55:1-119.

Muldoon MF, Barger SD, Ryan CM, et al. 2000. Effects of lovastatin on cognitive function and psychological well-being. Am J Med, 108:538-46.

Muldoon MF, Ryan CM, Sereika SM, et al. 2004. Randomized trial of the effects of simvastatin on cognitive functioning in hypercholesterolemic adults. Am J Med, 117:823-9.

NCEP 2001. Expert Panel on Detection, Evaluation, and Treatment of High Blood Cholesterol in Adults. 2001. Executive Summary of The Third Report of The National Cholesterol Education Program (NCEP) Expert Panel on Detection, Evaluation, and Treatment of High Blood Cholesterol In Adults (Adult Treatment Panel III). JAMA, 285:2486-97.

Neil HA, DeMicco DA, Luo D, et al.; CARDS Study Investigators. 2006. Analysis of efficacy and safety in patients aged $65-75$ years at randomization: Collaborative Atorvastatin Diabetes Study (CARDS). Diabetes Care, 11:2378-84.

Nissen SE, Tuzcu EM, Schoenhagen P, et al. 2004. Effect of intensive compared with moderate lipid-lowering therapy on progression of coronary atherosclerosis: a randomized controlled trial. JAMA, 291:1071-80.

Nissen SE, Tuzcu EM, Schoenhagen P, et al. 2005. Statin therapy, LDL cholesterol, C-reactive protein, and coronary artery disease. $N$ Engl $J$ Med, 352:29-38.

Olsson AG, Schwartz GG, Szarek M, et al. 2007. Effects of high-dose atorvastatin in patients $\geq 65$ years of age with acute coronary syndrome (from the myocardial ischemia reduction with aggressive cholesterol lowering [MIRACL] study). Am J Cardiol, 99:632-5. 
Pedersen TR, Kjekshus J, Berg K, et al; Scandinavian Simvastatin Survival Study Group. 1994. Randomised trial of cholesterol lowering in 4,444 patients with coronary heart disease: The Scandinavian Simvastatin Survival Study (4S). Lancet, 344:1383-9.

Pedersen TR, Faergeman O, Kastelein JJP, et al. 2005. High-dose atorvastatin vs usual-dose simvastatin for secondary prevention after myocardial infarction. The IDEAL study: a randomized controlled trial. JAMA, 294:2437-45.

Piamsomboon C, Laothavorn P, Saguanwong S, et al. 2002. Efficacy and safety of atorvastatin $10 \mathrm{mg}$ every other day in hypercholesterolemia. J Med Assoc Thai, 85:297-300.

Prueksaritanont T, Zhao JJ, Ma B, et al. 2002. Mechanistic studies on metabolic interactions between gemfibrozil and statins. J Pharmacol Exp Ther, 301:1042-51.

Rasmussen JN, Gislason GH, Abilstrom SZ, et al. 2005. Statin use after acute myocardial infarction: a nationwide study in Denmark. $\mathrm{Br} \mathrm{J}$ Pharmacol, 60:150-8.

Ray KK, Bach RG, Cannon CP, et al.; PROVE IT-TIMI 22 Investigators. 2006. Benefits of achieving the NCEP optional LDL-C goal among elderly patients with ACS. Eur Heart J, 27:2310-6.

Roberts CG, Guallar E, Rodriguez A. 2007. Efficacy and safety of statin monotherapy in older adults: a meta-analysis. J Gerontol A Biol Sci Med Sci, 62:879-87.

Rosamond W, Flegal K, Friday G, et al. 2007. Heart disease and stroke statistics - 2007 update. A report from the American Heart Association statistics committee and stroke statistics subcommittee. Circulation, 115:e69-172.

Rubin SM, Sidney S, Black DM, et al. 1990. High blood cholesterol in elderly men and the excess risk for coronary heart disease. Ann Intern Med, 113:916-20.

Sacks FM, Pfeffer MA, Moye LA, et al. 1996. The effect of pravastatin on coronary events after myocardial infarction in patients with average cholesterol levels. (Cholesterol and Recurrent Events Investigators). N Engl J Med, 335:1001-9.

Schartl M, Bocksch W, Koschyk DH, et al. 2001. Use of intravascular ultrasound to compare effects of different strategies of lipid-lowering therapy on plaque volume and composition in patients with coronary artery disease. Circulation, 104:387-92.

Schwartz GG, Olsson AG, Ezekowitz MD, et al.; Myocardial Ischemia Reduction with Aggressive Cholesterol Lowering (MIRACL) Study Investigators. 2001. Effects of atorvastatin on early recurrent ischemic events in acute coronary syndromes: the MIRACL study: a randomized controlled trial. JAMA, 285:1711-8.

Seljeflot I, Tonstad S, Hjermann I, et al. 2002. Reduced expression of endothelial cell markers after 1 year treatment with simvastatin and atorvastatin in patients with coronary heart disease. Atherosclerosis, 162: $179-85$.
Sever PS, Dahlof B, Poulter NR, et al. 2003. Prevention of coronary and stroke events with atorvastatin in hypertensive patients who have average or lower-than-average cholesterol concentrations, in the Anglo-Scandinavian Cardiac Outcomes Trial-Lipid Lowering Arm (ASCOT-LLA): a multicentre randomised controlled trial. Lancet, 361:1149-58.

Shepherd J, Cobbe SM, Ford I, et al. 1995. Prevention of coronary heart disease with pravastatin in men with hypercholesterolemia. West of Scotland Coronary Prevention Study Group (WOSCOPS). $N$ Engl J Med, 333:1301-7.

Shepherd J, Blauw GJ, Murphy MB, et al. 2002. PROspective Study of Pravastatin in the Elderly at Risk. Pravastatin in elderly individuals at risk of vascular disease (PROSPER): a randomised controlled trial. Lancet, 360:1623-30.

Shipley MJ, Pocock SJ, Marmot MG. 1991. Does plasma cholesterol concentration predict mortality from coronary heart disease in elderly people? 18 year follow up in the Whitehall Study. BMJ, 303:89-92.

Smith JC Jr, Allen J, Blair SN, et al. 2006. AHA/ACC guidelines for secondary prevention for patients with coronary and other atherosclerotic vascular disease: 2006 update: endorsed by the National Heart, Lung and Blood Institute. Circulation, 113:2363-72.

Szapary L, Horvath B, Marton Z, et al. 2004. Short-term effect of low-dose atorvastatin on haemorrheological parameters, platelet aggregation and endothelial function in patients with cerebrovascular disease and hyperlipidemia. CNS Drugs, 18:165-72.

Thompson GR, Naoumova RP, and Watts GF. 1996. Role of cholesterol in regulating apolipoprotein B secretion by the liver. J Lipid Res, 37:439-47.

Tonkin AM, Eckermann S, White H, et al. 2006. Cost-effectiveness of cholesterol-lowering therapy with pravastatin in patients with previous acute coronary syndromes aged 65 to 74 years compared with younger patients: results from the LIPID study. Am Heart J, 151:1305-12.

[UN] Population Division, DESA, United Nations. 2001. World Population Ageing 1950-2050. [online]. Accessed 27 Sept 2007. URL: http://www. un.org/esa/population/ publications/worldageing 19502050.

van Wissen S, Trip MD, Smilde TJ, et al. 2002. Differential hs-CRP reduction in patients with familial hypercholesterolemia treated with aggressive or conventional statin therapy. Atherosclerosis, 165: 361-66.

Ward S, Lloyd Jones M, Pandor A, et al. 2007. A systematic review and economic evaluation of statins for the prevention of coronary events. Health Technol Assess, 11:1-160, iii-iv.

Wenger NK, Lewis SJ, Herrington DM, et al.; Treating to New Targets Study Steering Committee and Investigators. 2007. Outcomes of using high- or low-dose atorvastatin in patients 65 years of age or older with stable coronary heart disease. Ann Intern Med, 147:1-9.

Zhou S, Chan SY, Goh BC, et al. 2005. Mechanism-based inhibition of cytochrome P450 3A4 by therapeutic drugs. Clin Pharmacokinet, 44:279-304. 